\title{
Gift from Uhlenbeck Funds Karen EDGE Fellowship
}

\section{Sophia D. Merow}

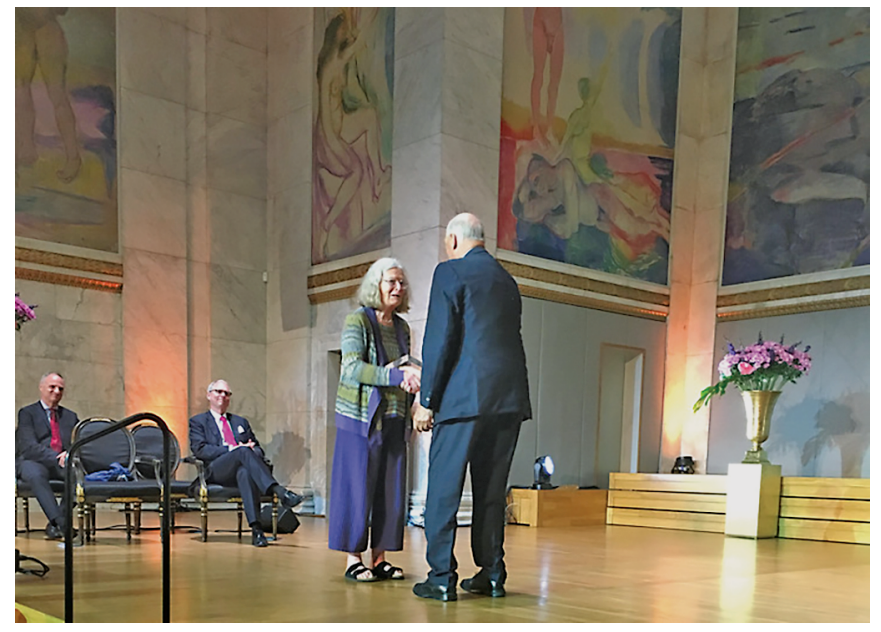

Figure 1. Karen Uhlenbeck accepts congratulations from King Harald V of Norway.

Hours after Karen Uhlenbeck learned she had been awarded the 2019 Abel Prize, a journalist asked her a question she was unprepared to answer: What would she do with the prize money? ${ }^{1}$

"It had not crossed my mind," Uhlenbeck later recalled.

By the time a congratulatory email from Rhonda Hughes arrived, however, Uhlenbeck had come to the beginnings of a decision.

"Even though she was in the middle of a media storm," Hughes remembers, "she replied and said that she wanted to talk about how to use the Prize money. She was thinking of using it to support mathematicians who were underrepresented minorities."

Sophia D. Merow is special projects editor and Notices assistant. Her email address is merow.notices@gmai 1 .com.

${ }^{1}$ The Abel Prize comes with a monetary award of six million Norwegian kroner.

For permission to reprint this article, please contact: reprint-permi ssion aams.org.

DOI: https://dx.doi.org/10.1090/noti2017
Uhlenbeck credits her husband, fellow mathematician Robert Williams, and the February 2019 New York Times article $^{2}$ about Edray Goins with influencing her thought process.

"The description of the difficulties of minority mathematicians in being accepted rang a bell," she says of the latter. Uhlenbeck thinks that while the environment for women in research mathematics has greatly improved in her lifetime, there's still work to be done to ensure would-be mathematicians of all demographics feel welcome. "It seemed timely and appropriate to turn attention onto groups that are still not comfortable and at home in mathematics," she says.

With a philanthropic direction in mind, Uhlenbeck then did what she had, "at a ripe old age, learned is the right thing to do." She sought help from people whose work in the relevant area she respected and opened up a conversation with Hughes.

In 1998, Hughes and Sylvia Bozeman, of Bryn Mawr and Spelman Colleges, respectively, founded the Enhancing Diversity in Graduate Education (EDGE) Program with the goal of increasing the number of women, particularly those from underrepresented groups, who earn PhDs in the mathematical sciences. Uhlenbeck was aware of EDGE from its inception, but her "first close encounter" (Bozeman's words) with the program came in 2008, when EDGE sponsored the Promoting Diversity at the Graduate Level in Mathematics forum at MSRI. She served on the conference's organizing committee and gave one of the opening addresses.

Uhlenbeck saw in EDGE, which began as a summer bridge program, something missing from her own efforts to address the gender imbalance in mathematics. Uhlenbeck and Chuu-Lian Terng cofounded Women and Mathematics (WAM), an outreach program first connected with

\footnotetext{
2"For a Black Mathematician, What It's Like to Be the 'Only One" (https://nyti.ms/2tpBwW4)
} 
Park City Mathematics Institute and now administered by the Institute for Advanced Study (IAS), and through her involvement with that initiative Uhlenbeck had learned how to encourage women to pursue graduate work in mathematics-but only if they came to WAM with solid preparation.

"We were able to design a program for women with enough background, but we were unsuccessful in reaching minorities and less well-prepared undergraduates," Uhlenbeck explains. "The EDGE program did something we would have liked to do."

Uhlenbeck finds EDGE's list of graduates-as of 2019, the program boasts one hundred PhDs-impressive. "How many women PhDs in mathematics from underrepresented minorities would there be," she asks, "without this program?"

In the weeks and months following the Abel Prize ceremony in Oslo (see Figure 1), a plan for leveraging Uhlenbeck's winnings to encourage underrepresented minorities in mathematics took shape. Uhlenbeck talked to Hughes, who looped the EDGE Foundation's board of directors into the conversation. "I trust people who have done good things, and who have a working organization in place," says Uhlenbeck. She happily left it to the EDGE veterans to hammer out the details of what became the Karen EDGE Fellowship Program (see Figure 2), which will award its first three fellowships in May.
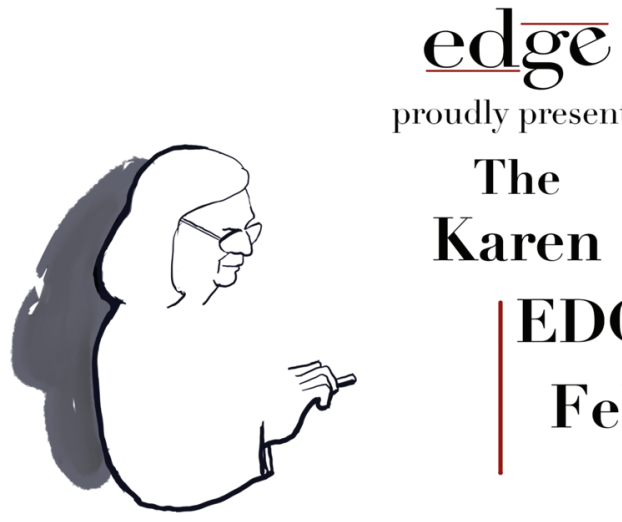

proudly presents

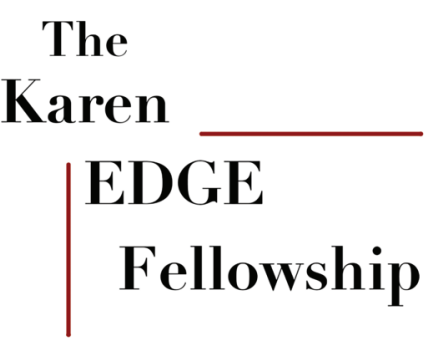

Figure 2. The newly established Fellowship's logo

Per Uhlenbeck's wishes and in keeping with EDGE tradition, the Karen EDGE Fellowship will serve underrepresented minorities, but it also, Hughes says, represents "a considerable broadening" of EDGE's mission. The Fellowship will welcome applicants of all gender identities, for one thing, and will focus on mid-career mathematicians. Even after they've become ineligible for the ample mentoring and fellowship opportunities available to graduate students and newly minted PhDs, Bozeman says, "all mathematicians continue to need the support of the mathematics community in order to develop and thrive." Many mathematicians are sympathetic to colleagues just starting out, but by mid-career, Uhlenbeck observes, "the expectation is that you will become a mentor and encourage younger people, while demands from family and society as a whole intensify. I think it is at mid-career that one enters the firing line."

The Karen EDGE Fellowship will "support and enhance" the research programs and collaborations of mid-career mathematicians with funds- $\$ 8,000$ per year for three years-to offset the cost of travel and supplies associated with a proposed research project. Through a partnership with the Institute, fellows will enjoy one expenses-paid trip per year to IAS, where an annual conference will encourage contact between awardees and senior members of the research community. While the fellows will no doubt benefit from their time in Princeton, Uhlenbeck points out that the Institute will profit too. "The Women and Mathematics Program at IAS introduced many young women to IAS," she says, "and paved the way to improving attitudes and the environment for women at IAS." Uhlenbeck also looks forward to personally meeting researchers with whom she otherwise might not cross paths: "Some good math will surely come out of it!"

Members of the mathematics community interested in supporting the "good math" of a diverse cohort of up-andcomers can be a part of the Karen EDGE Fellowship effort. Uhlenbeck could have earmarked her donation to endow one or two fellowships, but she opted instead to directly fund many. "I am hoping that my gift will inspire other mathematicians to donate money for endowments," she says, "but I am too old and impatient to wait indefinitely to see something happen."

EDGE thus has Uhlenbeck to thank for both her financial contribution and the example she has set for her peers. "I applaud the generosity of spirit which Karen Uhlenbeck exhibited in this gift and in her life work, always 'lifting as she climbs,'" says Bozeman of Uhlenbeck's donation. "We truly hope that others will see this as an area of need and want to contribute to a meaningful enterprise where they can help make a difference in the diversity of the mathematics community at its highest levels." 


\section{COMMUNICATION}

A Word from Karen. I would like to encourage mathematicians to consider making donations to the EDGE Foundation for the endowment for the fellowships. Also to get to know personally some of the remarkable men and women who are succeeding at mathematics who should not remain at the edges of the community. We all experience what it is to be outside the community. The first day at a new job, the first visit to a foreign math department where everybody knows everybody and nobody talks to us. Even worse, trying to switch fields and having nobody willing to explain anything. Actually, I think the very best mathematicians are good at accepting everybody who is interested in mathematics. We are natural teachers and sometimes good listeners. Just remember this!

See https: //www. edgeforwomen.org/karen -edge-fellowship-program for additional details of the Karen EDGE Fellowship.

For recent Notices coverage of Uhlenbeck's mathematics, see https://www. ams.ora/iournals/notices /201903/rnoti-p303.pdf

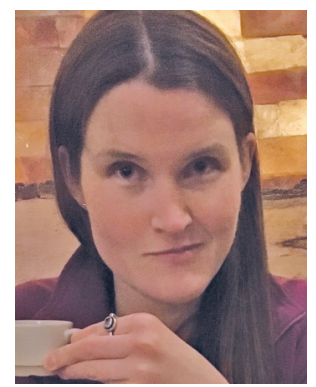

Sophia D. Merow

\section{Credits}

Photo of Abel Prize ceremony is courtesy of Elizabeth Boluch Wood, IAS.

Karen EDGE Fellowship logo design is by Tarah Paul, TaiDanae Bradley, and John de Pillis.

Author photo is by David Gabel.

\section{JOIN THE AMS... \\ or renew your membership today}

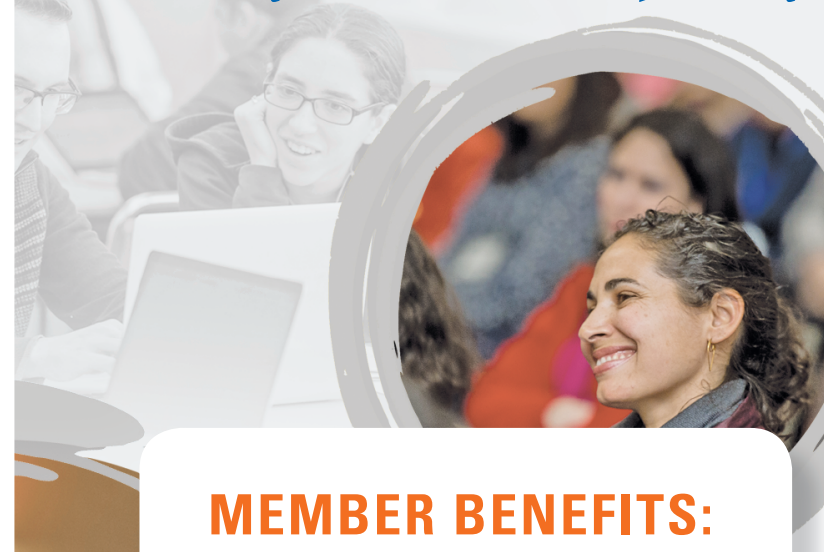

- Individual AMS members receive free standard shipping on orders delivered to addresses in the United States (including Puerto Rico) and Canada

- Discounts on AMS publications including MAA Press books

- Subscriptions to Notices and Bulletin

- Discounted registration for world-class meetings and conferences

- Access to online AMS Member Directory

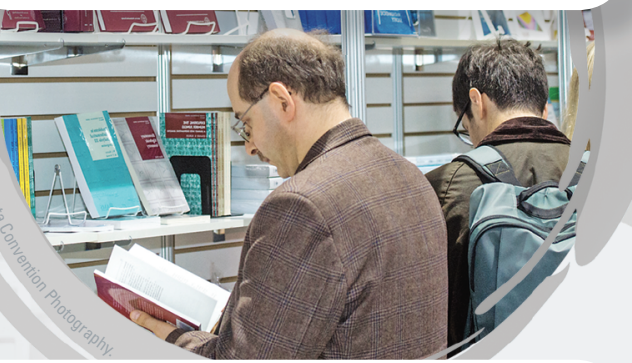

Learn more and join online at www.ams.org/membership.

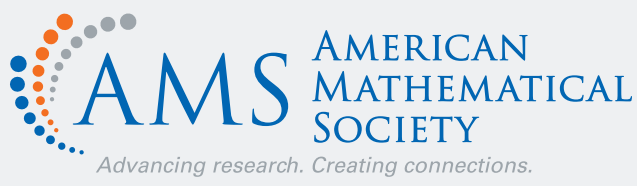

